\title{
Design, consumo e uso subversão da função: detecção de objetos do cotidiano que são apropriados por crianças para uso lúdico
}

Design, consumption and use function subversion: detection of everyday objects that are adopted by children for playful use

Valéria Ramos Friso ${ }^{[1]}$, Paula da Cruz Landim ${ }^{[2]}$, João Carlos Riccó Plácido da Silva ${ }^{[3]}$

Resumo: Apesar dos inúmeros brinquedos desenvolvidos especificamente para as crianças são encontrados muitos dos objetos de uso cotidiano em ambiente lúdico, os quais se tornaram obsoletos para os adultos. A partir dessa evidência surgiu essa pesquisa, que trouxe questões a cerca do comportamento do consumidor, do usuário, e como isso interfere no ciclo de vida do produto. Buscamos entender como se dá o consumo bem como o que significam as características encontradas nos objetos do cotidiano.

Palavras Chave: Design. Consumo. Crianças. 
Abstract: In spite of the numerous toys developed specifically for children, many of the everyday objects in a playful environment are found, which have become obsolete for adults. From this evidence emerged this research, which brought questions about the behavior of the consumer, the user, and how the design of the product interferes in this exchange of applications. We seek to understand how consumption takes place as well as what the characteristics found in everyday objects mean.

Keywords: Design. Consumption. Children.

\section{INTRODUÇÃO}

Brinquedos infantis são projetados por grandes empresas baseando-se em faixa etária, gênero, normas de segurança entre outros. Analisando caixas de brinquedo e em conversa com os responsáveis pelas crianças pode-se constatar que muitos dos objetos de uso cotidiano que estavam ali eram obsoletos para os adultos. Isso levou a uma reflexão sobre até que ponto isso revelaria um consumo desnecessário, e então o descarte precoce, e qual o valor que aqueles produtos passavam a ter, então, nas mãos das crianças. A partir daí surgiu essa pesquisa, que trouxe à superfície questões a cerca do comportamento do consumidor, do usuário, e como o design do produto se interfere nesse câmbio de aplicações. Para tanto era necessário encontrar casas com crianças que pudessem corroborar a existência dos objetos em questão no ambiente lúdico, investigar os espaços, detectar as características de design dos elementos e traduzir os resultados para entender o ciclo de vida doméstico desses produtos. Buscamos entender como se dá o consumo bem como o que significam as características encontradas nos objetos do cotidiano.

Os materiais, formas e cores podem ser definidos com base em diversas questões, sejam necessidades do usuário, requisitos técnicos ou mercadológicos, porém sua implicação no uso não esta necessariamente atrelada a esse componente inicial. As crianças exploram o entorno sob uma ótica muito peculiar. O que para nós é um abjeto comum, frívolo, sem atrativos, para ela é um elemento rico em possibilidades. É um engano achar que a exploração se dá pelo desco- 
nhecimento do significado do objeto. Em pesquisa anterior pudemos constatar que em um primeiro momento a criança identifica o objeto, compreende sua função e sua razão de existir, e em um segundo momento desconstrói essa relação para gerar uma nova leitura do material.

O lado interessante em se investigar caixas de brinquedos em ambiente doméstico é que essas apresentam nitidamente a função de camuflar entre a decoração da casa o universo de objetos explorados pela criança na atividade lúdica. Assim não há grandes preocupações quanto à classificação ou seleção desses produtos como acontece nos ambientes institucionais. As caixas de brinquedos se mostram uma fonte bastante rica de informações sobre a atividade da criança e sua relação com o design das peças. Daí nasce a questão principal da pesquisa: Como o design do produto interfere no abandono do objeto pelo adulto e na apropriação pela criança? Investigar esse fenômeno e entender a trajetória que o produto percorre nos ajudaria a entender as relações de consumo induzido e espontâneo.

O objetivo do presente estudo é compreender o ciclo de vida dos produtos e como o fenômeno pode ser relacionado com a apropriação dos objetos de uso cotidiano em ambiente lúdico doméstico, traçam uma relação entre o design e o abandono inicial e a apropriação posterior desse, gerando assim uma reflexão sobre como isso pode ser levando em consideração no desenvolvimento do produto.

\section{O DESIGN DO OBJETO COTIDIANO}

Os objetos de uso cotidiano são um importante alvo de trabaIho para o design. Devido ao seu consumo frequente e contato íntimo com o indivíduo, esses carregam consigo além de especificações técnicas e funcionais interessantes, uma grande carga emocional.

Para a presente pesquisa utilizamos a definição de Moles (1981), que um objeto é algo artificial, ou seja, que sofreu alguma interferência física ou semântica, com um caráter submisso à vontade do homem. Segundo Lefebvre +1954), 
quando se abstrai ou extrai do vivido todas as atividades especializadas e determinadas, o que permanece é a vida cotidiana. Assim consideramos objetos de uso cotidiano os materiais apropriados pelo homem que são usados de forma fácil, sem especialidade ou esforço específico.

A revolução industrial, reforçada pelos avanços tecnológicos posteriores trouxeram aos objetos novas características formais e mecânicas. As mais claras são a leveza dos materiais, a qualidade de acabamento, e a facilidade de manipulação, sem necessidade de montagem ou instruções muito complexas. As ligas metálicas tornaram-se mais eficientes, os polímeros trouxeram propriedades mecênicas inovadoras, e os processos produtivos eram capazes de fornecer produtos mais completos com menos etapas de fabricação. Essas características trouxeram inclusive para o cotidiano objetos que eram de uso técnico. Em algum tempo toda casa teria um telefone, uma máquina de costura ou de escrever. O design e a publicidade foram cruciais naquele momento. O século XX em especial foi marcado por um intenso trabalho de geração de consumo. Amparadas no status social as industriais criavam necessidades e variações do mesmo produto, estilizando-os para o ambiente industrial, ou comercial ou residencial, e criando novos produtos como diferentes tipos de sabão para diferentes tipos de limpeza (Forty, 2007). Moles (1981) explica que o papel da Natureza das coisas passou a ser diminuído pelo artificial, de forma que o ser procura dar resposta as suas necessidades sociais através da promoção de objetos.

No âmbito econômico, o designer tomou para si a missão de analisar os grupos e as necessidades particulares dos usuários para dar conta desta variabilidade solicitada pelo mercado. O domínio da emoção passa a ser um elemento importante para manter o sistema industrial a partir de então, definindo o padrão estético dos produtos. Na questão da usabilidade as simulações virtuais e a facilidade de prototipagem propiciaram um exercício projetual mais dinâmico e pro- 
dutos mais funcionais. Os produtos passam a assumir formas ousadas e elaboradas sem prejudicar o resultado funcional.

\section{A SEGURANÇA DA CRIANÇA}

Os brinquedos estruturados industrializados devem seguir normas de segurança, e não podem oferecer riscos à saúde ou integridade física da criança. Entretanto essas normas não são acessíveis pelos pais, que fornecem esses objetos para as crianças. Observando as normas podemos destacar alguns possíveis problemas da subversão do uso desses objetos.

A AMN (Asociación MERCOSUR de Normalización), por meio do comitê setorial de brinquedos CSM 04 regulamenta a produção industrial de brinquedos do Mercado Comum do Sul e é integrado pelos organismos nacionais de normalização dos países membros. (ASOCIACIÓN MERCOSUR DE NORMALIZACIÓN, 2007)

A Norma NM 300-1 visa minimizar potenciais perigos associados aos brinquedos, e são considerados riscos atribuídos a sua utilização para os modos de utilização pretendidos, bem como para os modos de utilização não pretendidos, tido como abuso razoavelmente previsível, o que a torna aplicável aos brinquedos não estruturados. Essa parte da Norma MERCOSUL especifica critérios aceitáveis para o formato, tamanho, contorno, espaçamento dos brinquedos, bem como critérios aceitáveis para propriedades peculiares para determinadas categorias de brinquedos (por exemplo ângulos mínimos de extremidade para determinados brinquedos de montar). Os objetos foco da normalização são brinquedos a serem utilizados por crianças até 14 anos, porém os requisitos variam de acordo com a idade para o qual é destinado. A norma define os requisitos para os seguintes fatores:

- Uso normal

- Abuso razoavelmente previsível

- Materiais

- Partes pequenas 
- Formato, tamanho e comprimento de determinados brinquedos

- Bordas cortantes

- Pontas

- Projeções

- Hastes e arames de metal

- Filme plástico ou sacos plásticos para embalagens e brinquedos

- Cordas e elásticos

Diversos desses fatores estão presentes nos objetos de uso cotidiano que podem estar acessíveis as crianças. $O$ designer deve estar atento a esse fenômeno para ajudar a prevenir possíveis acidentes. Entender o trajeto que o objeto faz até chegar ao ambiente lúdico poderá dar indícios da iminência do uso secundário do produto que está em desenvolvimento pelo designer, podendo usar tal argumento durante a projetação.

\section{CONSUMO E DESCARTE}

A relação entre consumidor e objeto nos interessa, bem como a do usuário com o objeto, uma vez que, conforme podemos observar, as duas posições não se confundem necessariamente. Moles estudou amplamente essas relações e define o objeto como "mediador entre o homem e o mundo", ou "entre cada homem e a sociedade " (Moles, 1981). Podemos intuir que em relações de consumo a influência social se sobressai, enquanto que no uso propriamente dito há um direcionamento imposto pela realidade. Os calçados femininos são um bom exemplo. É muito comum vermos sapatos novos sendo doados ou guardados sem uso. Isso por que a compra se deu para atender a um padrão social muitas vezes estético, porém, quando chegada a fase de uso, não há adequação de forma ou estilo com a realidade da usuária, tornando o produto inútil. Moles descreve o ciclo dos objeto em duas situações. O circuito elementar do objeto seria quando parte do mercado, entrara na esfera pessoal e é descartado 
no lixo. Porém, ele aborda um fenômeno que é detectado em algumas culturas de consumo como a norte-americana onde o esquema se torna mais complexo. Nesses casos os objetos obsoletos vão para o sotão, ou seja para uma reserva, onde se valorizariam lentamente podendo retornar como produto para antiquários (Figura 1).

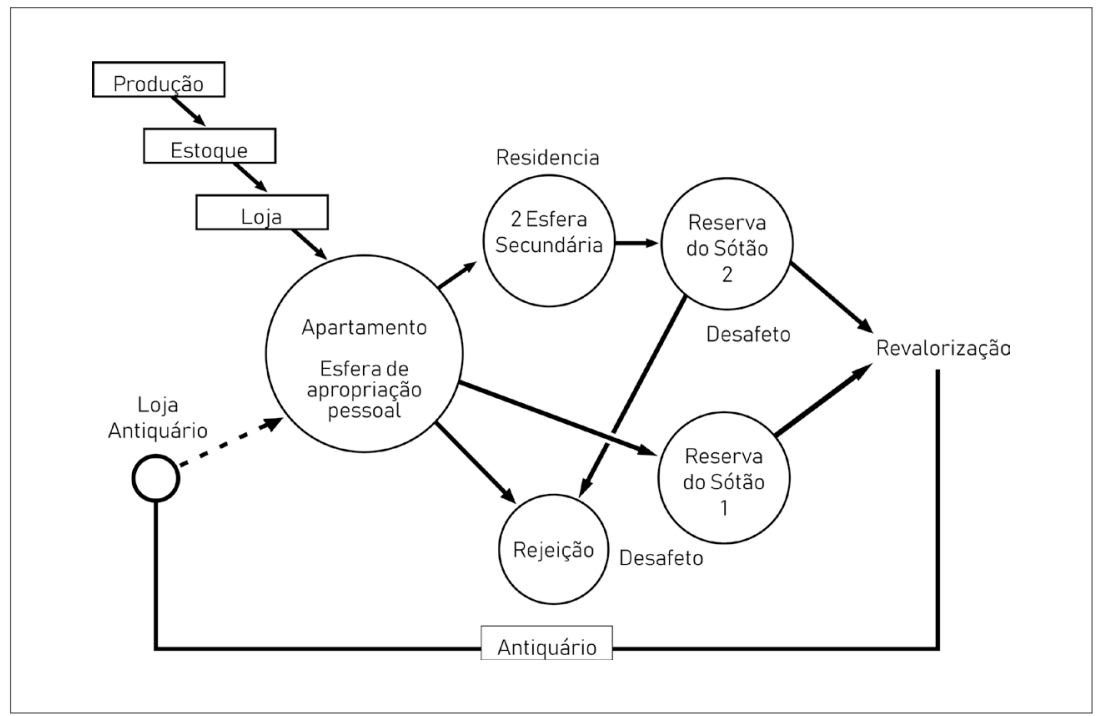

O enorme crescimento das lojas de utilidades é um reflexo do alto consumo desse tipo de produto. Além disso, as mercadorias estão constantemente agregadas a preços baixos e fixos, mostrando a pequena implicação material sobre os custos gerado pelas tecnologias industriais e de materiais. Tal cenário nos levou a uma valorização da frivolidade no consumo, um desinteresse sobre a história das peças e sobre seu destino. Vemos atualmente um contra movimento que busca resgatar esses princípios através de produções em pequenas escalas e materiais e processos mais duradores, entretanto esta ainda não é uma premissa no consumo da grande massa.

Durante muito tempo a relação entre o homem e a natureza foi unilateral. As pesquisas sobre ecologia passaram a permear diversas áreas diferentes, inclusive no design. Sur-
Figura 1 - O ciclo dos objetos de Moles. Fonte: Moles (1981) adaptado pelo autor 
giu a noção de interdependência dos fenômenos, e da retroalimentação da natureza. (CAPRA, 1999). As tecnologias fabris transformam e combinam elementos naturais com tamanha complexidade que muitas vezes em sua composição se torna difícil o reconhecimento de sua matéria prima. Em muitos casos os resíduos gerados são compostos de diferentes materiais que criam uma aparente instabilidade sistêmica, ou seja, não são facilmente reaproveitados pela natureza. O homem passou a apropriar-se sem restrições dos recursos naturais, pois sua única função era servi-lo. O crescimento econômico e tecnológico davam a falsa impressão de que os recursos materiais seriam ilimitados. (CAPRA, 1999).

\section{A APROPRIAÇÃO LÚDICA DE OBJETOS DO COTIDIANO}

Os brinquedos infantis são objetos com baixo direcionamento de uso, uma vez que sua intenção deve ser a exploração lúdica pela criança. Assim é esperado que sejam os que sofram maiores intervenções pelo usuário, devido a liberdade de interpretação e a pouca rigidez que eles apresentam. "Entende-se por brinquedos qualquer estimulo material fornecido a criança" (BOMTEMPO, 1986, pág. 149). A origem dos primeiros brinquedos industrializados dos quais se tem registro são miniaturas de produtos cotidianos direcionadas a adultos em Nuremberg, no século XVIII, que caíram nas graças das crianças. No século XIX começaram a ser produzidas peças maiores, voltadas agora para crianças, como bonecas de porcelana, carrinhos de madeira e soldadinhos de chumbo, criando um novo consumidor e reforçando o desejo de posse da criança.

Os brinquedos podem surgir da necessidade infantil de imitação. Como afirma Raquel Zumbano Altman (2004), as crianças indígenas aprendem as funções adultas através de miniaturas daquelas que serão suas ferramentas. Sementes, madeira, palha, e diversos outros elementos encontrados em seu ambiente também são usados em suas brincadeiras. De acordo com Benjamin (2002), os antigos brinquedos foram impostos como objetos de cultos para as crianças, e se torna- 
ram brinquedos graças a sua imaginação. Brincando as crianças desenvolvem sua percepção de sentidos e formas, e são capazes de redefinir as coisas, dando-lhes nova configuração. Assim, qualquer objeto pode se tornar um brinquedo. Objetos cotidianos são frequentemente adotados pelas crianças para uso em suas brincadeiras. O brinquedo nada mais é que um "objeto suporte da brincadeira" sendo eles estruturados (desenvolvidos para esse fim) ou não estruturados (concebidos com outra finalidade). (KISHIMOTO 1997).

O material e a novidade são variáveis importantes no comportamento do brincar (Berlyne, 1969; Quilitch e Risley, 1973). Um estudo publicado em 1986 da Universidade de São Paulo (USP) buscou comparar o interesse que brinquedos industrializados e não industrializados despertavam nos bebês. O levantamento dos objetos a serem aplicados foi feito por meio de pesquisa com as mães das crianças. Então os objetos foram aplicados em ambiente de pesquisa utilizando a técnica de amostra de tempo (time sampling) onde eram introduzidos objetos novos a cada $10 \mathrm{~min}$. bebes de 15 meses. O estudo mostrou não haver preferência significativa pelos brinquedos industrializados sobre os não industrializados. (BOMTEMPO, 1986)

Assim pode-se entender os objetos de uso cotidiano utilizados na atividade lúdica como brinquedos, apesar de não ser sua função declarada. A partir desse contesto configura-se um ciclo peculiar para os produtos (Figura 2) 


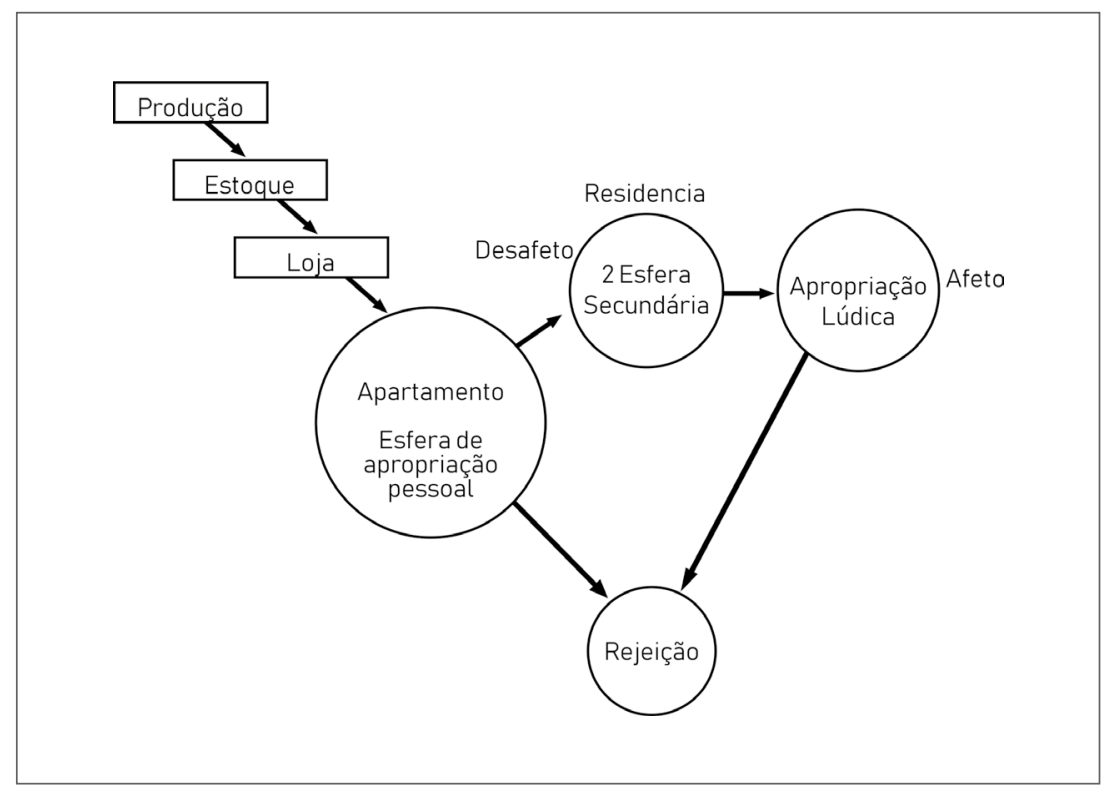

Figura 2 - 0 ciclo dos brinquedos não estruturados. Fonte: Autor, baseado em Moles (1981).

Quando surge o desafeto e o objeto segue para a esfera secundária, há possibilidade de apropriação pela criança e geração de afeto desta pelo produto. Porém essa nova relação se dá a partir de outras necessidades e leitura uma vez que não foi comprado, e sim garimpado, e não há compromisso social ou funcional durante o uso.

\section{PESQUISA DE CAMPO}

A investigação nos ambientes lúdicos se configura uma pesquisa Exploratória, de abordagem Qualitativa. Os materiais utilizados para documentação das informações foram: Câmera fotográfica e filmadora Sony Cyber-shot DSC-W230, Prancheta papel e caneta e Software Microsoft Word 2013;

Foram selecionadas 8 casas com crianças entre 3 e 6 anos, com ou sem irmãos, que não apresentassem deficiências físicas ou mentais. Foram agendadas as visitas e apresentado Termo de Consentimento Livre esclarecido para assinatura do responsável. Na casa procuramos localizar onde ficavam armazenadas a maior variedade de brinquedos das crianças, aqueles que não ficam organizados por categorias 
ou expostos para decorar o ambiente. Localizados os brinquedos, esses eram analisados e distribuídos no chão, de forma que fosse possível detectar posteriormente através de registro fotográfico (Figura 3) quais objetos estavam entre os brinquedos mesmo não tendo a brincadeira como função primordial. A identidade das crianças que estavam presentes no momento do registro foi preservada.

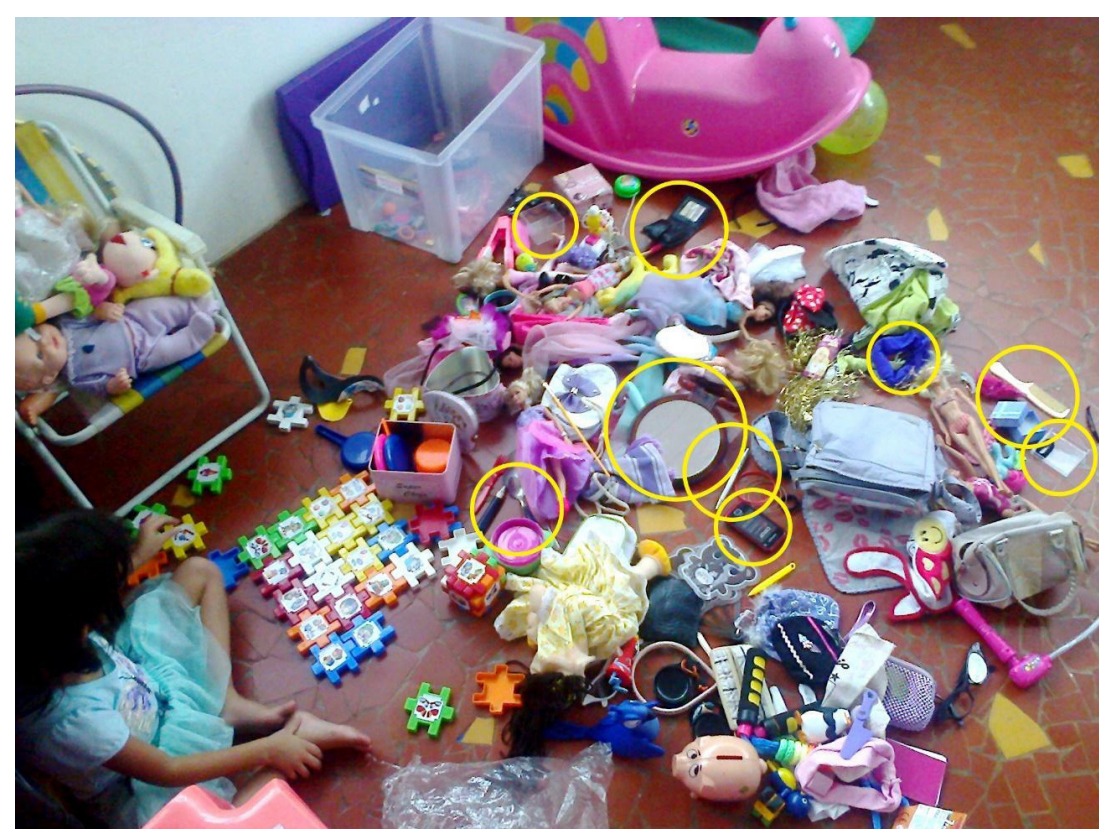

Figura 3 - Fotografia retirada durante investigação da caixa de brinquedos de uma casa pesquisada. Fonte: do autor.

\section{RESULTADOS}

Com as fotos foi possível destacar os objetos localizados e depois tabulá-los segundo suas características. Foram criados termos para relacionar de forma mais abrangente funções comuns entre diferentes objetos, conforme descrito no Quadro 1. 


\section{Quadro 1: classificação e objetos por categoria. Fonte: do autor.}

\begin{tabular}{|c|c|}
\hline Acessórios & Pulseira de relógio, carteira, óculos. \\
\hline Acondicionamento & $\begin{array}{l}\text { Caixa plástica, embalagem de iogurte, tampa } \\
\text { plástica, embalagem de remédio, recipiente } \\
\text { plástico, saboneteira, tampa plástica, caixa } \\
\text { para ferramentas, recipiente plástico. }\end{array}$ \\
\hline Alimentação & $\begin{array}{l}\text { Colher, forminha de doce, palito de } \\
\text { picolé, copo plástico rígido, espátula. }\end{array}$ \\
\hline Fonte elétrica & Pilha, carregador de bateria. \\
\hline $\begin{array}{l}\text { Componentes } \\
\text { de construção }\end{array}$ & $\begin{array}{l}\text { Elástico de borracha, parafuso, } \\
\text { componente de moveis. }\end{array}$ \\
\hline Cuidados Pessoais & $\begin{array}{l}\text { Espelho, seringa, pente, } \\
\text { prendedor de cabelo, venda. }\end{array}$ \\
\hline $\begin{array}{l}\text { Instrumentos de } \\
\text { comunicação }\end{array}$ & Celular. \\
\hline $\begin{array}{l}\text { Instrumentos } \\
\text { de Trabalho }\end{array}$ & $\begin{array}{l}\text { Câmera, estetoscópio, lanterna, } \\
\text { microfone, pincel, calculadora, trena, } \\
\text { caneta, canetinha, câmera fotográfica. }\end{array}$ \\
\hline Limpeza & Pá. \\
\hline
\end{tabular}

A partir dos dados foram produzidos gráficos para ilustrar o volume e quantidade em incidências de acordo com sua função primária. Encontramos que os objetos mais encontrados são os que estão relacionados a alimentação e instrumentos de trabalho com 10 objetos cada, seguidos pelos objetos de acondicionamento com nove incidências e objetos para cuidados pessoais com sete unidades (Figura 4). 


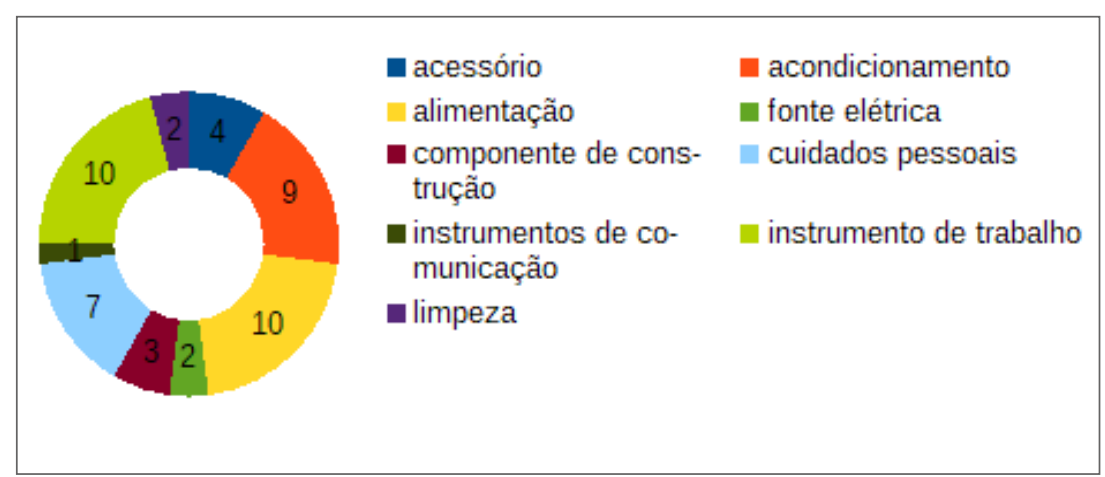

Quanto ao número de casas onde o mesmo objeto foi encontrado, objetos da alimentação, acondicionamento, componentes de construção e instrumentos de trabalho constavam em todas as caixas investigadas (Figura 5).

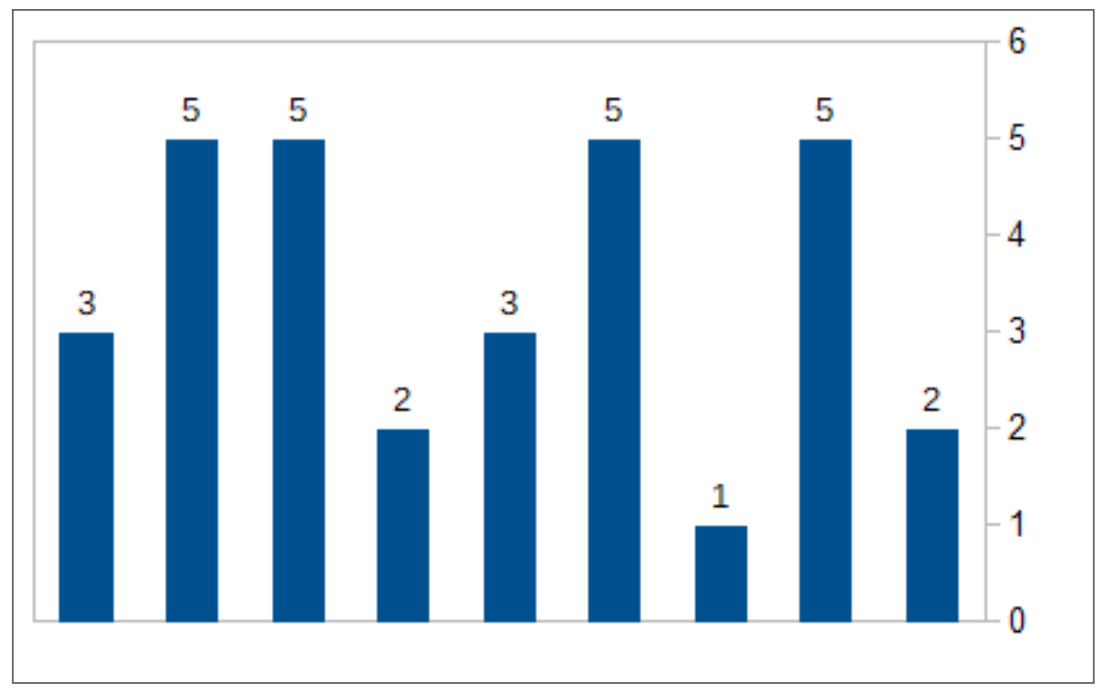

Desta forma se destacaram os instrumentos de trabalho e alimentação com o máximo de incidência e em todas as casas, e os objetos de acondicionamento que apareceram nove vezes e em todas as casas.

A maior parte dos instrumentos de trabalho encontrados eram produtos que perderam sua função por terem se quebrado o que justificaria o descarte. Fica subentendido que o
Figura 4 - Quantidade de objetos encontrados no total das casas pesquisadas por classificação. Fonte: o autor.
Figura 5 - Quantidade de casas pesquisadas onde foram encontrados cada classe de objetos. Fonte:o autor. 
valor desses produtos está intimamente ligado a função, uma vez que são usados para obter resultados objetivos. Por outro lado reflete a obsolescência precoce, uma característica advinda da revolução industrial.

Os objetos usados originalmente para alimentação caracterizam-se pelo baixo preço e consumo em grandes volumes. São objetos encontrados nas mais diversas formas em lojas de utilidades e variedades, e cujo valor se ampara em relações de diferenciação social. O desafeto nesse caso ocorre a medida que o produto se torna fora de moda, ou que as necessidades de consumo mudam.

Os objetos de acondicionamento são produtos já descartáveis e outros incompletos, que perderam sua função. Apesar de perderem sua função não perderam necessariamente seu funcionamento mecânico, pois podem ser tampados e destampados por pressão ou por rosca. Isso sugere uma produção ineficiente, uma vez que o produto, ainda íntegro, foi deslocado da sua função primária e tornou-se um objeto obsoleto pelo desafeto imediato a partir do conteúdo.

\section{CONSIDERAÇÕES FINAIS}

Perceber que o ciclo de vida do objeto pode ser mais complexo do que apenas compra uso e descarte, leva-nos a uma reflexão sobre outros fatores a serem considerados no desenvolvimento do produto. Mostra também um potencial não explorado do objeto que pode encontrar uma função distinta daquela determinada inicialmente pelo projeto, e vem solucionar novas necessidades apresentadas, nesse caso, pelo consumidor infantil.

O design de produtos tem sua participação no fenômeno abordado, uma vez que interfere na durabilidade de produtos com apelo funcional, na estética e tendências de consumo dos objetos de diferenciação social e é um dos responsáveis por determinar o ciclo de vida de objetos descartáveis.

Os objetos encontrados e analisados comprovam o ciclo do brinquedo não estruturado, trazendo à superfície a im- 
portantes questionamentos a respeito da saúde das crianças e o consumo exacerbado de objetos com rápido descarte. A análise dos objetos estudados nos permite duas vias de reflexão. Em um primeiro momento, apresenta diferentes causas e prazos para a desapropriação e apropriação dos objetos de seu lugar primordial, apresentando que o desafeto pode ser gerado pela perda da função primária, o desinteresse a partir de status social ou instantaneamente após seu primeiro uso, o que não interfere na geração de afeto pela criança que se apropria desses. A segunda se refere a como o ciclo desses produtos pode implicar sobre a atividade lúdica, uma vez que não há um controle sobre os referidos aspectos de usabilidade desses objetos enquanto brinquedos. A princípio podemos pensar em garantir objetos mais seguros para usos adversos ou gerar alternativas para evitar que cheguem às mãos das crianças.

A partir da presente investigação poderão ser desenvolvidos estudos mais específicos, com estudos de caso mais pontuais, bem como sugeridas alternativas de desenvolvimento de produtos que levam em consideração os pontos levantados.

\section{REFERÊNCIAS}

ALTMAN, Raquel Zumbano Brincando na história.

In: DEL PRIORE, M. (org.) História das crianças no

Brasil. 4.ed. São Paulo: Contexto, 2004. p. 231-258

ASOCIACIÓN MERCOSUR DE NORMALIZACIÓN.

NM 300-1:2002/ERR.3:2008: Segurança de

brinquedos - Parte 1: Propriedades gerais,

mecânicas e físicas. Rio de Janeiro, 2007.

BENJAMIN, Walter. Reflexões sobre a criança, o

brinquedo e a educação. Editora 34, 2002. 
BERLYNE, Daniel Ellis. Laughter, Humor and Play. In: G. Lindsey e E. Aronson (Eds.). - The Handbook of Social

Psychology. Massachussetts, Addison Wesley Pub. Co., 1969.

BOMTEMPO, Edda. . Psicologia do Brinquedo: Aspectos

Teóricos e Metodológicos. São Paulo: Nova Estella, 1986.

CAPRA, F. A teia da vida: uma nova compreensão

científica dos sistemas vivos. Trad. Newton

Roberval Eichemberg. São Paulo: Cultrix, 1999.

FORTY, A . Objeto de desejo; Tradução Pedro

Maia Soares. São Paulo: Cosac Naify, 2007

KISHIMOTO, T, M. O jogo e a educação infantil.

São Paulo: Livraria Pioneira, 1994.

LEFEBVRE, H. Sociologie de la vie

quotidienne. Paris. Parche, 1954

MOLES, Abraham A Teoria dos objetos. Rio de Janeiro: Edições Tempo Brasileiro, 1981.

QUILITCH, H. R.; RISLEY, T. R. - The effects of play material

on social play. Journal of Applied Behavior Analysis, 1973. 